\title{
Ralstonia solanacearum Differentially Colonizes Roots of Resistant and Susceptible Tomato Plants
}

\author{
Denise Caldwell, Bong-Suk Kim, and Anjali S. Iyer-Pascuzzi
}

Department of Botany and Plant Pathology, Purdue University, West Lafayette, IN 47906.

Accepted for publication 19 January 2017.

\begin{abstract}
Ralstonia solanacearum is the causal agent of bacterial wilt and infects over 200 plant species in 50 families. The soilborne bacterium is lethal to many solanaceous species, including tomato. Although resistant plants can carry high pathogen loads (between $10^{5}$ and $10^{8} \mathrm{CFU} / \mathrm{g}$ fresh weight), the disease is best controlled by the use of resistant cultivars, particularly resistant rootstocks. How these plants have latent infections yet maintain resistance is not clear. $R$. solanacearum first infects the plant through the root system and, thus, early root colonization events may be key to understanding resistance. We hypothesized that the distribution and timing

of bacterial invasion differed in roots of resistant and susceptible tomato cultivars. Here, we use a combination of scanning electron microscopy and light microscopy to investigate $R$. solanacearum colonization in roots of soil-grown resistant and susceptible tomato cultivars at multiple time points after inoculation. Our results show that colonization of the root vascular cylinder is delayed in resistant 'Hawaii7996' and that, once bacteria enter the root vascular tissues, colonization in the vasculature is spatially restricted. Our data suggest that resistance is due, in part, to the ability of the resistant cultivar to restrict bacterial root colonization in space and time.
\end{abstract}

The soilborne bacterium Ralstonia solanacearum causes bacterial wilt disease and is particularly devastating to tomato (Hayward 1991; Huet 2014). $R$. solanacearum typically gains access to host root systems through natural wounds caused by the emergence of lateral roots or through wounds acquired as roots grow through the soil. After entering the root, bacteria move to the root vasculature, where they multiply in the xylem and subsequently spread into the shoot (Digonnet et al. 2012; Turner et al. 2009; Vasse et al. 1995). The bacterium secretes an exopolysaccharide (EPS) that likely leads to physical blockage of xylem tissue, resulting in wilting and eventual death (Denny 2000; Denny and Baek 1991; McGarvey et al. 1999; Saile et al. 1997; Schell 2000). Xylem colonization appears to be critical to disease progress because $R$. solanacearum mutants impaired in xylem colonization do not cause wilting in plants (Plener et al. 2010; Vasse et al. 2000).

Like many root diseases, bacterial wilt is challenging to control. In tomato, resistance to $R$. solanacearum is quantitative, and the genes underlying resistance are unclear. The most effective method of disease control is through resistant cultivars (Huet 2014; Yuliar and Toyota 2015). One commonly used method is through grafting resistant rootstocks to susceptible scions, which significantly reduces bacterial wilt incidence in infected tomato fields (McAvoy et al. 2012; Rivard and Louws 2008). High levels of bacteria are present in taproots of both resistant and susceptible cultivars (Grimault and Prior 1993; Ishihara et al. 2012; McGarvey et al. 1999). Despite these latent infections, the success of grafting with resistant rootstocks to control disease suggests that roots may have defense mechanisms that are critical to whole-plant resistance. There is little information about root defense mechanisms, and the infection process in roots of resistant plants is not well understood. Understanding differences in the root infection process between resistant and susceptible tomato roots is critical for developing new avenues of disease control. Such knowledge will enable future work

Corresponding author: A. S. Iyer-Pascuzzi; E-mail address: asi2@purdue.edu

*The $\boldsymbol{e}$-Xtra logo stands for "electronic extra" and indicates that one supplementary table and two supplementary figures are published online.

(c) 2017 The American Phytopathological Society to focus on specific root cell types and tissues to identify genes which function in resistance in tomato roots.

In roots of susceptible tomato plants grown in liquid media, bacteria colonize the root external surface, spread to the intercellular spaces of the root cortex, and then invade the root vascular system, including xylem parenchyma and vessels (Digonnet et al. 2012; Turner et al. 2009; Vasse et al. 1995). Once in the root vasculature, they spread to the stem of the susceptible plant.

Several reports have shown that bacterial wilt resistance is associated with the restriction of bacterial spread within the stem (Grimault et al. 1994a,b, 1995; Nakaho and Allen 2009; Nakaho et al. 2004). In roots, EPS was found to be more widely distributed within vascular tissue of a susceptible compared with a resistant variety at 5 days after inoculation (McGarvey et al. 1999), suggesting that roots may also restrict bacterial colonization. However, bacterial distribution within roots of resistant plants has not been closely examined.

Resistant rootstocks are key for resistance to $R$. solanacearum and, thus, root anatomical and architectural analyses will likely provide insight about tomato mechanisms of resistance or susceptibility to $R$. solanacearum. Due to the importance of root xylem tissue in bacterial wilt disease, we hypothesized that differences in the timing and distribution of bacterial colonization of xylem tissue may be important for resistance. Specifically, we hypothesized that bacteria colonized the root vascular cylinder of resistant plants more slowly than in susceptible plants and that, once in the vascular cylinder, bacteria were distributed differently within xylem tissue in the resistant root compared with the susceptible root. Here, we use light microscopy and scanning electron microscopy (SEM) to examine the distribution of bacteria in roots of two resistant tomato varieties and two susceptible varieties at multiple time points after infection.

\section{MATERIALS AND METHODS}

Plant cultivars and growth conditions. Seed of resistant 'Hawaii7996' (H7996) (Solanum lycopersicum), resistant 'CRA66' (S. lycopersicum var. cerasiforme), susceptible 'Okitsu Sozai no. 1' (OS) (S. lycopersicum), and susceptible 'WestVirginia700' (WV) (S. pimpinellifolium) were surface sterilized with a $30 \%$ bleach solution for $5 \mathrm{~min}$, rinsed thoroughly with sterile distilled water 
$\left(\mathrm{ddH}_{2} \mathrm{O}\right)$, and placed at $4^{\circ} \mathrm{C}$ overnight. $\mathrm{H} 7996$ and CRA66 are two of the three primary sources of resistance to $R$. solanacearum, and likely derive their resistance from different wild tomato species (Hanson et al. 1998). Both varieties provide resistance to a range of $R$. solanacearum strains, including K60 (Chellemi et al. 1994; Grimault et al. 1994a; Hanson et al. 1998; Lebeau et al. 2011), although the range of strains and degree of resistance to a specific strain can differ (Lebeau et al. 2011). Seed of CRA66 and OS were obtained from INRA, and H7996 and WV from the University of Wisconsin. Seed were planted in flats with 36 rectangular cells, each containing 25 to $27 \mathrm{~g}$ of Propagation Mix (Sun Gro Horticulture). Plants were grown in a growth chamber at $28^{\circ} \mathrm{C}$ with a relative humidity of $70 \%$ and at a cycle of $16 \mathrm{~h}$ of day and $8 \mathrm{~h}$ of night. Seedlings were watered at the bottom of the flat and fertilized with Peters Excel 15-5-15 Cal-Mag Special 10 days after germination.

Bacterial strains, inoculum preparation, root inoculation, and sample numbers. The $R$. solanacearum species complex is divided into four phylotypes that largely correspond to geographical range (Prior and Fegan 2005). Strain K60 was first identified in North Carolina and is classified as phylotype IIA, sequevar 7 (Remenant et al. 2012). K60 was grown on casamino acid-peptone-glucose (CPG) agar at $28^{\circ} \mathrm{C}$ for $48 \mathrm{~h}$. Inoculum was prepared by flooding plates with sterile water and resuspending bacterial colonies to an optical density at $600 \mathrm{~nm}=0.1\left(1 \times 10^{8} \mathrm{CFU} / \mathrm{ml}\right)$. This inoculum was chosen because it is typical of other laboratory-based studies in that tomato-R. solanacearum pathosystem (Jacobs et al. 2012; McGarvey et al. 1999; Milling et al. 2011) and, specifically, of those that have investigated $R$. solanacearum colonization in planta (Grimault et al. 1994a, b, 1995; Vasse et al. 1995). Dilution plating was used to confirm the concentration after each set of inoculations.

Tomato plants at the three-leaf stage were either inoculated with the $R$. solanacearum inoculum or mock inoculated with sterile $\mathrm{ddH}_{2} \mathrm{O}$. For inoculation, seedlings (including the soil) were gently removed from their growth containers and transferred to a 10-by14-in. $(25.4 \times 35.6 \mathrm{~cm})$ plastic container. Approximately 1.5 liters of either inoculum $\left(\mathrm{K} 60\right.$ at $\left.1.0 \times 10^{8} \mathrm{CFU} / \mathrm{ml}\right)$ or sterile $\mathrm{ddH}_{2} \mathrm{O}$ was poured into the container to the root-shoot junction and allowed to soak for 5 min. Seedlings were transferred back to their rectangular containers and placed into a growth chamber with the conditions above.

For light microscopy, four replicates (i.e., independent growth and inoculations) were performed for $\mathrm{H} 7996$ and WV and three for CRA66 and OS. Three of the four replicates were also used for SEM for H7996 and WV (SEM was not done for CRA66 and OS). Within each replicate, for each cultivar, 36 plants were used: 18 plants were inoculated with $R$. solanacearum and 18 were mock inoculated with water. Three plants of each cultivar were harvested at each time point $(0,24,48,72$, and $144 \mathrm{~h}$ postinoculation [hpi]) for both mockinoculated and $R$. solanacearum-inoculated plants. The remaining three plants of each cultivar were not harvested but kept in the growth chamber to ensure that wilting occurred in the susceptible plants but not in the resistant plants.

For light microscopy, for each replicate, the three collected samples at each time point for each cultivar and treatment were sectioned with a rotary microtome (see below). Each sample was cut into 7- $\mu \mathrm{m}$ sections, and at least 90 sections for each sample were viewed. All sections with light microscopy were viewed with the $\times 10, \times 20$, and $\times 40$ objectives. Images of representative sections were taken at either $\times 20$ or $\times 40$, depending on the size of the root.

For SEM, only the 24-, 72-, and 144-hpi time points for both mock-inoculated and $R$. solanacearum-inoculated plants were used, with two plants per time point per replicate. Samples were cut into 30- $\mu \mathrm{m}$ sections, with three sections viewed per sample. SEM properties (magnifications, voltage, and spot size) for each SEM image in each figure are listed in Supplementary Table S1.

Root and hypocotyl harvest. Tomato plants were collected at $0,24,48,72$, and 144 hpi for both inoculated and mock-inoculated samples. The majority of the soil was removed from the root zone with a series of water dips. The remaining soil was brushed from roots using a soft paintbrush. The plants were transferred to a labeled storage container filled with water covering the root zone to ensure that the roots did not dry out.

Under a dissecting scope, the stem was cut from the root at the root-shoot junction. The 2 -cm section above the root-shoot junction was used for hypocotyl sectioning. All lateral roots were trimmed $2 \mathrm{~mm}$ from the primary root. Roots were cut $2.5 \mathrm{~cm}$ below the rootshoot junction. A second cut was made $2 \mathrm{~mm}$ from the end of the root, and this small piece was used for sectioning.

Confirmation of $\boldsymbol{R}$. solanacearum colonization. To confirm that the bacteria observed inside the root were $R$. solanacearum, we used Agdia ImmunoStrip tests for $R$. solanacearum (Agdia, Elkhart, IN). These strips test for $R$. solanacearum at the species level. For these tests, both mock- and $R$. solanacearum-inoculated roots were harvested and the topmost $2.5-\mathrm{cm}$ portion of the root (the same portion from which we took sections for microscopy) was used. Samples were ground in buffer and dilution plated onto CPG plates. Both the ground sample and individual colonies from the sample were tested with Agdia ImmunoStrips according to the manufacturer's instructions. These tests confirmed that the bacteria inside the roots were $R$. solanacearum. In addition to testing with immunostrips, for each replicate, we examined mock-inoculated roots of the same cultivar at the same time point. Bacteria were not observed inside mock-inoculated roots using either scanning or light microscopy.

Histological processes. The 2-mm samples were transferred to a 20 -ml scintillation vial with $5 \mathrm{ml}$ of fresh $1.5 \%$ glutaraldehyde $/ 2 \%$ formaldehyde in a $0.1-\mathrm{M}$ cacodylate buffer fixative solution using forceps. The scintillation vial with the $2-\mathrm{mm}$ sample was placed in a polycarbonate vacuum desiccator on low vacuum pressure for $2 \mathrm{~h}$. After $2 \mathrm{~h}$, the fixative was removed and the sample was rinsed with $0.1 \mathrm{M}$ cacodylate buffer. Samples were placed under low vacuum pressure for 15 min and rinsed two additional times with buffer.

Samples were dehydrated gradually under low vacuum pressure using a graded series of alcohols: $20 \%$ ethanol $(\mathrm{EtOH}), 50 \% \mathrm{EtOH}$, and a graded series of tert-butyl alcohol (TBA) IV. A $0.1 \%$ safranin O (Thermo Fisher Scientific, Waltham, MA) stain was added to TBA IV to assist in locating the sample. Samples were in each solution under low vacuum pressure for $15 \mathrm{~min}$. After the allotted time, the vacuum pressure was shut off but kept attached with pressure inside for a minimum of $4 \mathrm{~h}$. After removal of the TBA IV, the solution was replaced with $100 \%$ TBA and placed on top of the paraffin oven overnight. The entire process was repeated two more times. Fresh $100 \%$ TBA was added to cover all the tissue and liquid paraffin (melted Paraplast X-tra; Electron Microscopy Sciences, Hatfield, PA) was added to fill vials. The vials were kept at $56^{\circ} \mathrm{C}$ overnight or until melted, mixed, and returned to $56^{\circ} \mathrm{C}$ for a minimum of $24 \mathrm{~h}$. Paraffin was removed from vials and replaced with fresh molten paraffin two more times, with at least $24 \mathrm{~h}$ between changes. Tissue was embedded into a Peel Away Disposable Embedding Mold (Electron Microscopy Sciences) with fresh melted paraffin and left to $\mathrm{cool}$ at room temperature for $24 \mathrm{~h}$. A Leica/Reichert 2035 Microtome with Tissue-Tek Accu-Edge Disposable High Profile Microtome Blades (Electron Microscopy Sciences) was used to cut sections to a thickness of $7 \mu \mathrm{m}$. The sections were mounted on a slide covered with $\mathrm{ddH}_{2} \mathrm{O}$ and allowed to dry on a slide warmer for $2 \mathrm{~h}$.

Light microscopy. Samples were deparaffinized and stained with aqueous $0.05 \%$ Toluidine Blue (Amresco, Solon, $\mathrm{OH}$ ) stain for $10 \mathrm{~min}$. Sections were mounted on slides by placing Permount Mounting Medium (Electron Microscopy Sciences) onto the slide surface. Light microscope images were captured on an Olympus BX43 upright microscope with a SPOT Idea 5.0 Mp Color Digital CMOS camera.

SEM. Paraffin samples were cut to $30 \mu \mathrm{m}$, placed atop a $25-\mathrm{mm}$ circular coverslip covered with $\mathrm{ddH}_{2} \mathrm{O}$, and allowed to dry for $2 \mathrm{~h}$ on a slide warmer. After drying, the samples were deparaffinized in $100 \%$ fresh xylene for $5 \mathrm{~min}$, which was then repeated three additional times. Samples were allowed to dry (30 s), then placed on a 25.4-mm aluminum slotted specimen mount with double-sided tape. A line of silver conductive coating was laid down between the 
pin and the top of the coverslip. Samples were sputter coated using a Cressington turbo-pumped sputter coater. SEM samples were viewed using a FEI NOVA nanoSEM Field Emission Scanning Electron Microscope under high vacuum at $5.00 \mathrm{kV}$, Spot Size 3.0, and an Everhart Thornley detector for imaging.
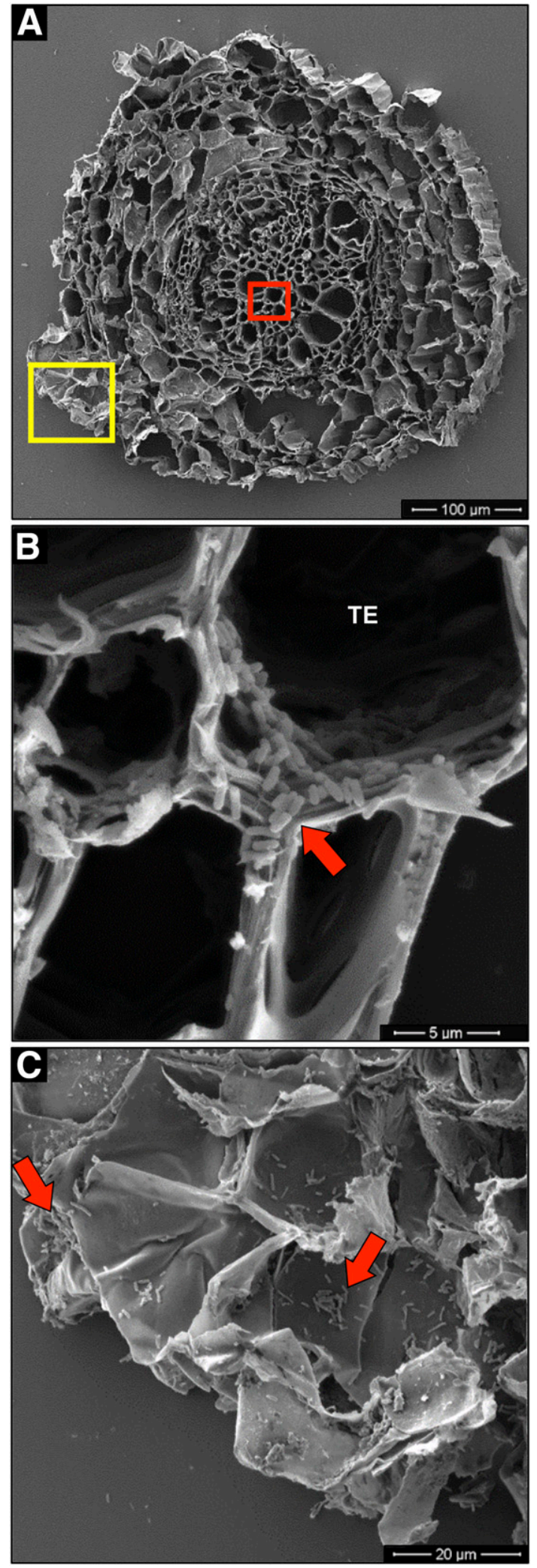

Fig. 1. Scanning electron microscopy cross-sections of $\mathrm{WV}$ at $24 \mathrm{~h}$ postinoculation. A, Root cross-section; B, magnified view of small box showing Ralstonia solanacearum colonizing tracheary elements; $\mathbf{C}$, magnified view of large box showing $R$. solanacearum colonizing the external root surface and cortical cells. TE $=$ tracheary element and arrows indicate bacteria.
Measurement of xylem vessel area. The area of the xylem vessels within a root section at 0 hpi was measured with ImageJ software. The vascular cylinder was outlined and the magic wand tool used to select the largest 20 xylem vessels within the region. Each vessel was measured using the "region of interest" tool, and the five
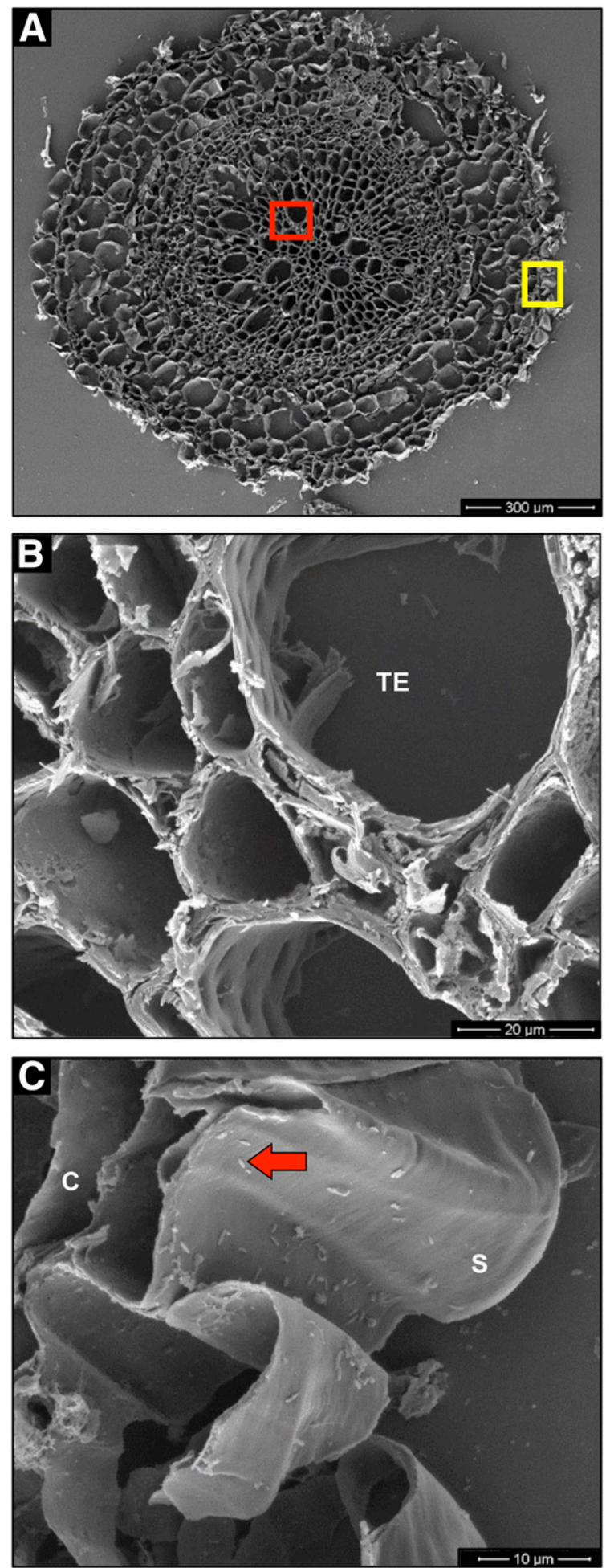

Fig. 2. Scanning electron microscopy cross-sections of H7996 at 24 h postinoculation (hpi). A, Root cross-section. B, magnified view of box near center showing tracheary elements in the vascular cylinder of H7996 at 24 hpi. No bacteria were observed in the tracheary elements or xylem parenchyma cells, C, Magnified view of box near edge showing bacteria (arrow) present on external surface of the root. $\mathrm{TE}=$ tracheary element, arrow indicates bacteria, $\mathrm{C}=$ cortex, and $\mathrm{S}=$ root external surface. 
vessels with the largest area were used in the analysis. Calculation of dimensions from the microscopic images was performed using a micrometer to determine the number of pixels in $10 \mu \mathrm{m}$. For each variety, at least two roots from four independent replicates were measured. Statistical analysis was performed in $\mathrm{R}$ on log-transformed data to meet the assumptions of the one-way analysis of variance.

\section{RESULTS}

$R$. solanacearum colonizes the root vascular cylinder of susceptible WV faster than that of resistant H7996. To examine the distribution of bacteria within resistant and susceptible roots, we first used SEM at 0, 24, and 72 hpi in resistant H7996 and susceptible WV.
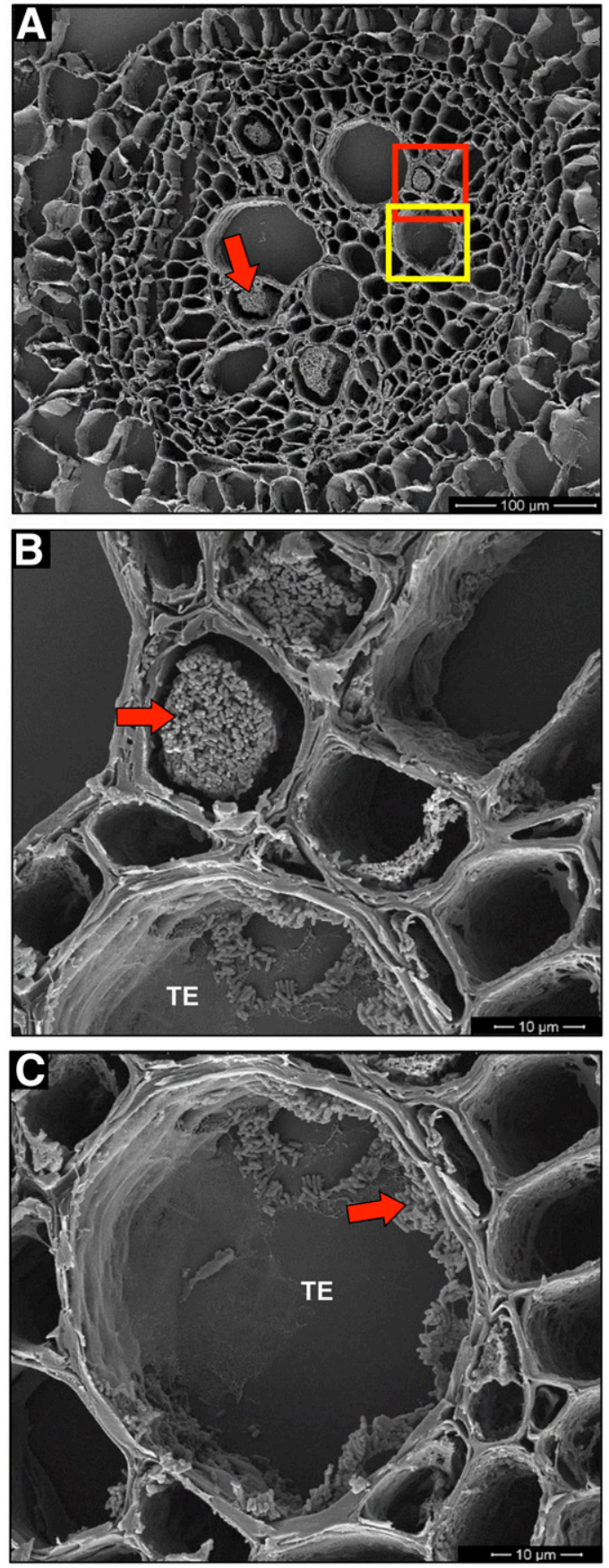

Fig. 3. Scanning electron microscopy cross-sections of $\mathrm{H} 7996$ at $72 \mathrm{~h}$ postinoculation (hpi). A, Root cross-section of H7996 at 72 hpi; B, magnified view of upper box showing bacteria masses in the smaller tracheary elements but mostly lacking attachment to the cell wall; and $\mathbf{C}$, magnified view of lower box shows a large tracheary element with bacteria along the wall. $\mathrm{TE}=$ tracheary element and arrow indicates bacteria.
SEM at 24 hpi revealed $R$. solanacearum colonization in the vascular cylinder of susceptible WV (Fig. 1A and B). The magnified view in Figure 1B shows $R$. solanacearum colonizing the tracheary elements. In addition to the vascular cylinder, bacteria were also found colonizing the root cortical cells and the surface of the root sample (Fig. 1A and C). In contrast, bacteria had yet to reach the root vascular cylinder in resistant H7996 (Fig. 2A and B). Instead, $R$. solanacearum was found primarily on cells of the external surface of the sample (Fig. 2C). Mock-inoculated roots of H7996 and WV revealed no bacteria (Supplementary Fig. S1). These data show that $R$. solanacearum colonizes the root vascular cylinder of susceptible WV at 24 hpi but, at that time point, has not reached the vasculature in resistant $\mathrm{H} 7996$.
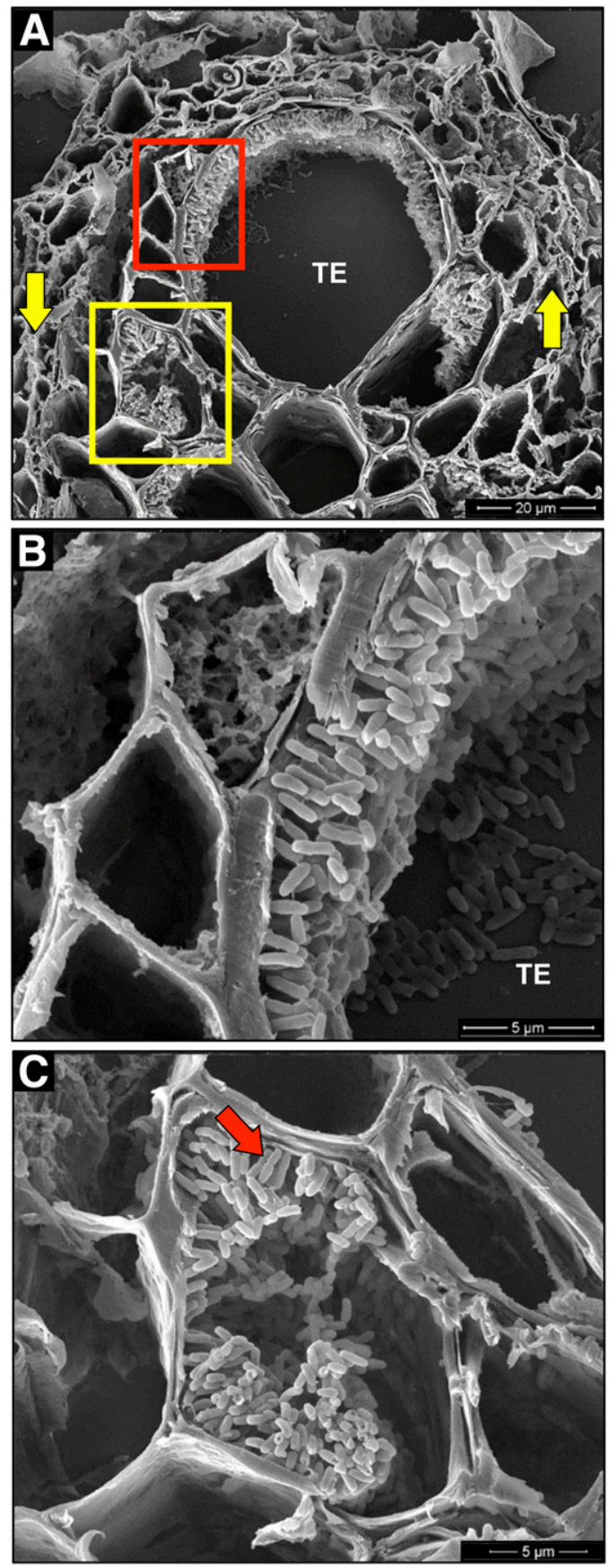

Fig. 4. Scanning electron microscopy cross-sections of WV at $72 \mathrm{~h}$ postinoculation. A, Root cross-section. Arrows point to collapsed xylem parenchyma cells. B, Magnified view of upper box showing bacteria mostly attached to the walls of the tracheary elements, $\mathbf{C}$, Magnified view of lower box showing tracheary element obstructed with bacteria. TE $=$ tracheary element and arrow indicates bacteria. 
Although bacteria were not observed in the root vascular cylinder of $\mathrm{H} 7996$ at $24 \mathrm{hpi}$, at $72 \mathrm{hpi}$, masses of $R$. solanacearum were present in several xylem tracheary elements of H7996 (Fig. 3A to C). Bacteria were occasionally located at the edges of large xylem vessels, with many not directly attached to the cell walls (Fig. 3C). In contrast, at $72 \mathrm{hpi}$ in susceptible WV, multiple tracheary elements within the vascular cylinder of the WV root were colonized with bacteria that appeared to be attached to the cell walls (Fig. 4A to C). Large meta-xylem elements were frequently colonized along the edges with masses of bacteria (Fig. 4A to C), whereas some smaller vessels were nearly completely filled with bacteria (Fig. 4C). Xylem parenchyma cells in WV occasionally collapsed (Fig. 4A, yellow arrows) but this was not observed in $\mathrm{H} 7996$ at 72 hpi (Fig. 3).

These data show that $R$. solanacearum colonizes the xylem of susceptible WV within 24 hpi but colonization of the vascular cylinder of resistant H7996 is delayed.

$\boldsymbol{R}$. solanacearum colonizes the root vascular cylinder of resistant $\mathbf{H 7 9 9 6}$ at $48 \mathrm{hpi}$. The temporal differences in colonization of H7996 and WV led us to examine more closely when the bacteria entered the root vasculature of H7996. For this, we used light microscopy with toluidine blue staining at five time points after infection $(0,24,48,72$, and $144 \mathrm{hpi})$ in resistant $\mathrm{H} 7996$ and susceptible WV (Fig. 5). With this stain, bacteria are colored dark blue (Renzi et al. 2012) (Supplementary Fig. S2).
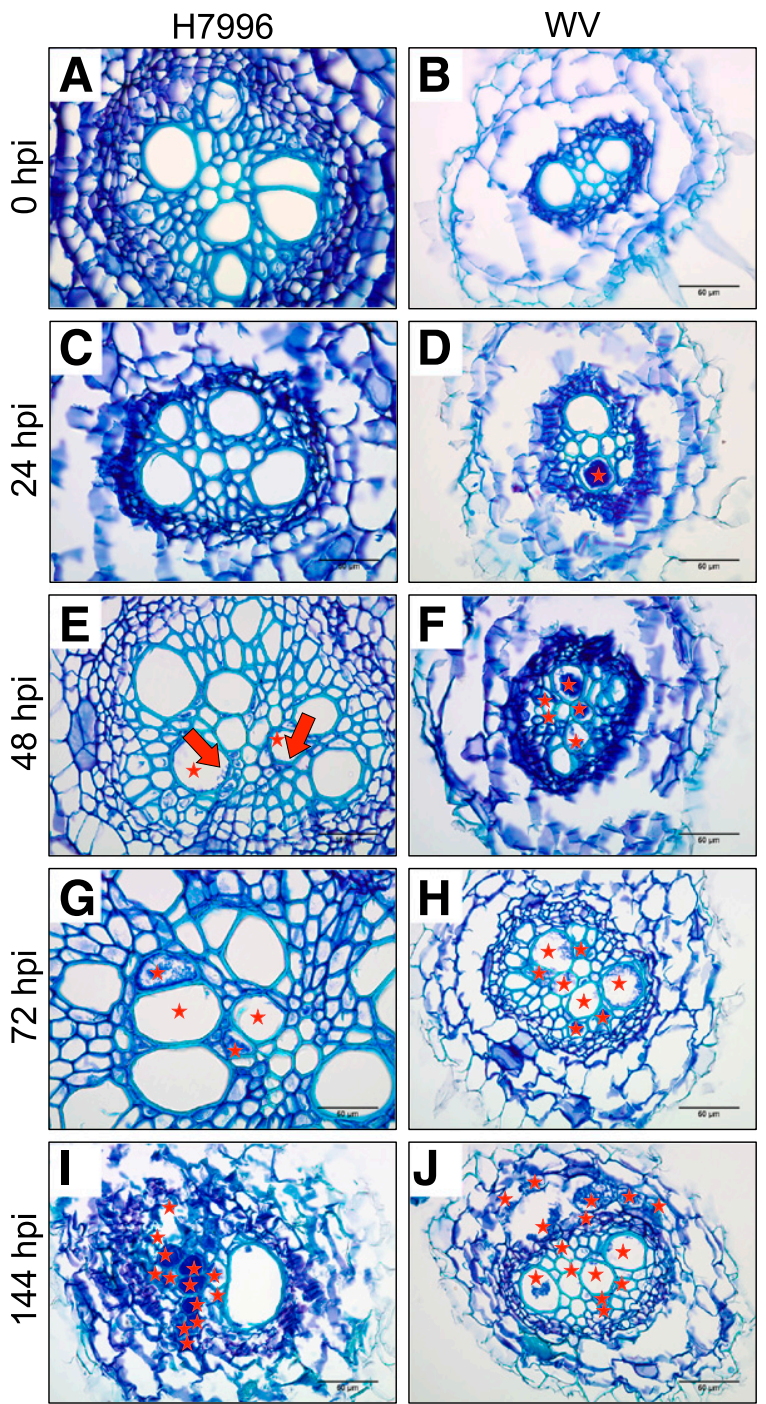

Fig. 5. Bacterial colonization in $\mathrm{H} 7996$ and $\mathrm{WV}$ at $0,24,48,72$, and $144 \mathrm{~h}$ postinoculation (hpi) observed with light microscopy. Red stars indicate cells in which bacteria are present. E, Arrows point to bacteria along the edge of the cell. Scale bar $=50 \mu \mathrm{m}$.
The light microscopy data confirm our SEM results that bacteria colonize the root vascular cylinder of resistant H7996 later than susceptible WV. At 0 hpi, both resistant H7996 (Fig. 5A) and susceptible WV (Fig. 5B) roots are free of bacterial colonization in the xylem. Consistent with our observations using SEM, bacteria are not present in the root vascular cylinder of $\mathrm{H} 7996$ resistant variety at 24 hpi (Fig. 5C) but are present in the larger xylem tracheary elements in WV at 24 hpi (Fig. 5D). The light microscopy revealed that bacteria are found along the edges of the tracheary elements in $\mathrm{H} 7996$ at 48 hpi (Fig. 5E) whereas, in WV, several large masses of bacteria are already seen within the tracheary elements by
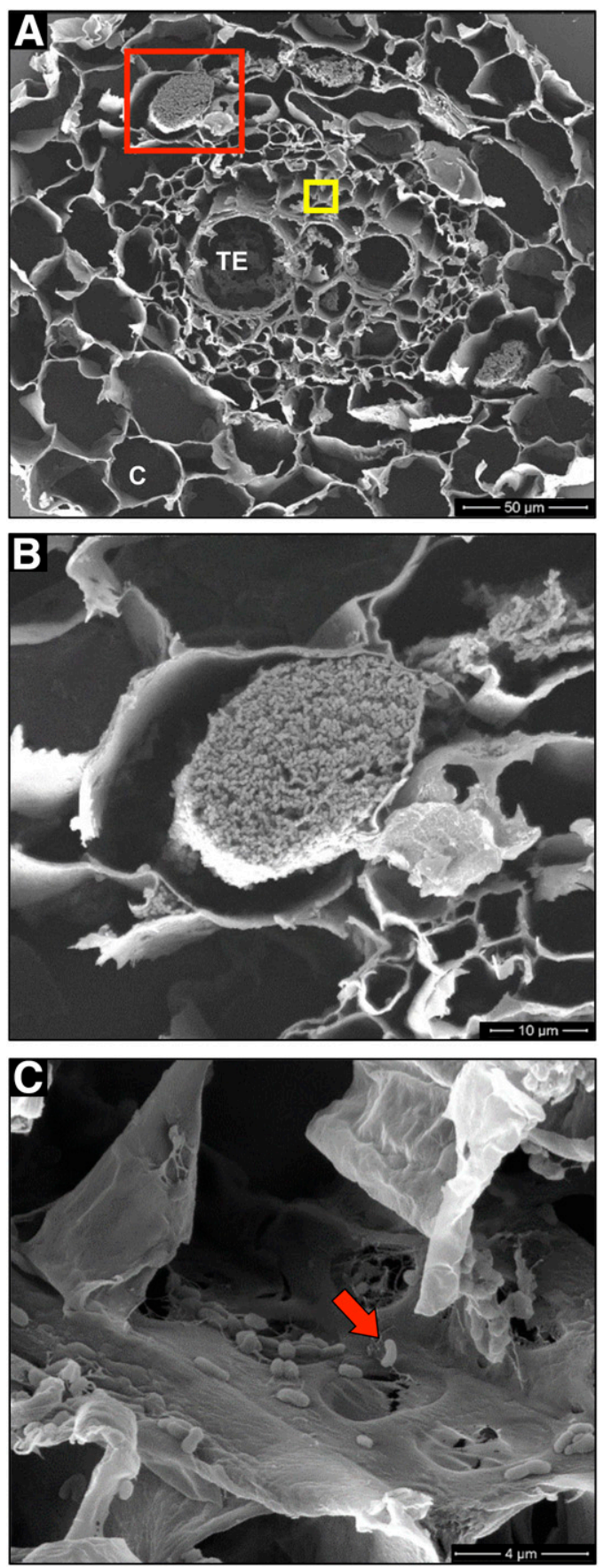

Fig. 6. Scanning electron microscopy cross-sections of WV at $144 \mathrm{~h}$ postinoculation. A, Cross section of WV root with large amounts of bacteria in cortex cells and vasculature. B, Magnified view of large box. A large mass of bacterial cells is visible within a cortex cell. $\mathbf{C}$, Magnified view of small box showing bacteria along the edge of a tracheary element next to pit membranes. $\mathrm{TE}=$ tracheary element, arrow indicates bacteria, and $\mathrm{C}=$ cortex . 
this time point (Fig. 5F). In line with the SEM results at $72 \mathrm{hpi}$, both H7996 and WV show an increase in bacteria within the vascular cylinder (Fig. 5G and $\mathrm{H}$ ) at this time point compared with 48 hpi. In WV, more xylem tracheary elements appear to be colonized at 72 hpi (Fig. 5H), including both large and smaller elements. Together, these data indicate that $R$. solanacearum enters the vascular cylinder of resistant H7996 between 24 and 48 hpi.

At $144 \mathrm{hpi}$, the spatial distribution of $R$. solanacearum colonization is restricted in roots of $\mathbf{H 7 9 9 6}$ compared with susceptible WV. The above results showed that resistant roots delay colonization of the root vasculature, a key tissue in disease progress. To understand the spatial distribution of the pathogen in H7996 and WV plants at later time points, we examined root sections at $144 \mathrm{hpi}$. Results from SEM revealed that, by $144 \mathrm{hpi}, R$. solanacearum colonizes the root cortex cells of WV (Fig. 6A and B). Further, the bacteria appear to spread throughout cells of the root vasculature in susceptible WV (Fig. 6A, light microscopy shown in Figure 5J).

In contrast, at $144 \mathrm{hpi}$, bacteria were not observed within the root cortex of the resistant line (Fig. 7A). Significant colonization was observed in a region of the xylem between the protoxylem poles in H7996 (Fig. 7A and B) but the larger xylem vessels were still without bacteria at this time point. Similar results were observed with light microscopy for both resistant H7996 (Fig. 5I) and susceptible WV (Fig. 5J).

The pattern of $R$. solanacearum root colonization differs in a second resistant cultivar. To examine whether the patterns of colonization observed in H7996 and WV were similar in other resistant and susceptible varieties, we used light microscopy to
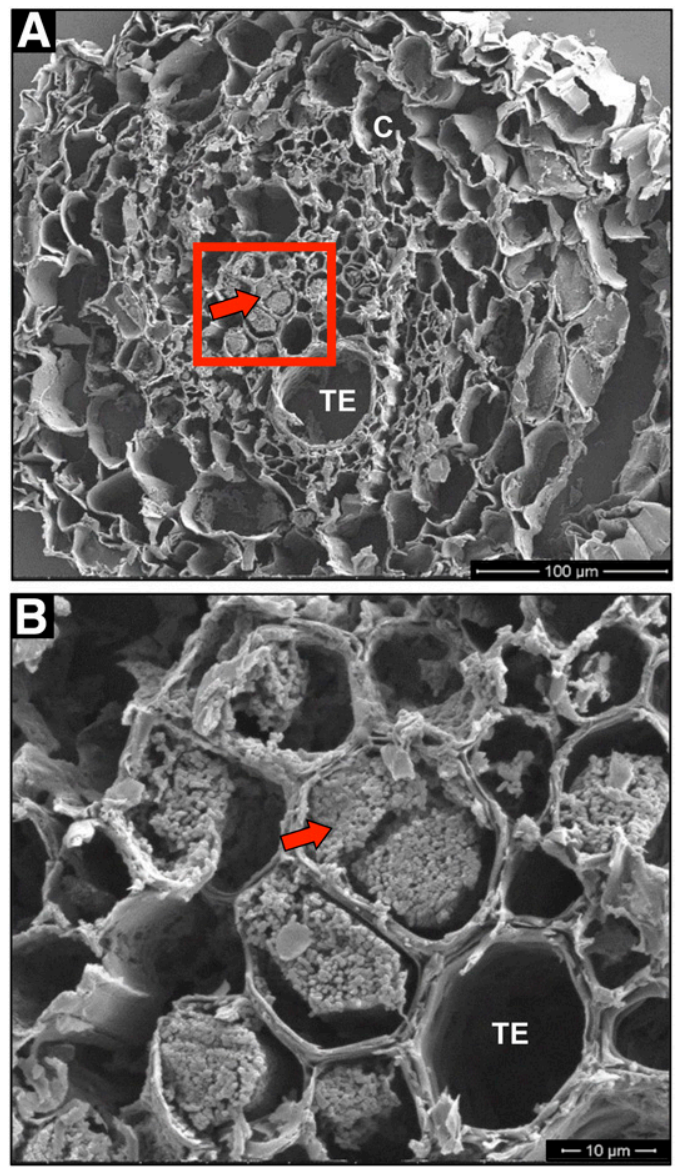

Fig. 7. Scanning electron microscopy cross-sections of H7996 at $144 \mathrm{~h}$ postinoculation (hpi). A, Root cross-section of H7996 at 144 hpi and B, magnified view of box showing colonies of Ralstonia solanacearum in the metaxylem located between the protoxylem poles. $\mathrm{TE}=$ tracheary element, arrow indicates bacteria, and $\mathrm{C}=$ cortex. examine bacterial colonization in resistant CRA66 and moderately susceptible OS at 0, 24, 48, 72, and $144 \mathrm{hpi}$ (Fig. 8). As expected, no colonization was seen at 0 hpi for either resistant CRA66 (Fig. 8A) or susceptible OS (Fig. 8D). Similar to the roots of resistant H7996, no bacteria were observed within the root vascular cylinder of resistant CRA66 at 24 hpi (Fig. 8) whereas, at 48 hpi, roots of resistant CRA66 were colonized within the vascular cylinder (Fig. 8). However, at $72 \mathrm{hpi}$, in contrast to what we observed with roots of resistant $\mathrm{H7996}$ (Fig. 3), a large area of the vascular cylinder of CRA66 was colonized by $R$. solanacearum, with bacteria present in multiple large metaxylem elements at this time point (Fig. 8B). At 144 hpi, resistant CRA66 showed colonization of multiple tracheary elements in the vascular cylinder, including large vessels (Fig. 8C). These data reveal that $R$. solanacearum colonization of resistant CRA66 is initially similar but then differs from that of $\mathrm{H} 7996$.

Surprisingly, susceptible OS showed a slightly different pattern of bacterial colonization than susceptible WV. In contrast to WV, OS did not show $R$. solanacearum colonization at $24 \mathrm{hpi}$. However, similar to $\mathrm{WV}$, from 48 hpi onward, OS roots were heavily colonized (Fig. 8E and F).

Xylem vessel size at the time of inoculation does not correlate with resistance or susceptibility. Because we observed that bacteria could completely occlude xylem vessels, we questioned whether xylem vessel size played a role in resistance or susceptibility.
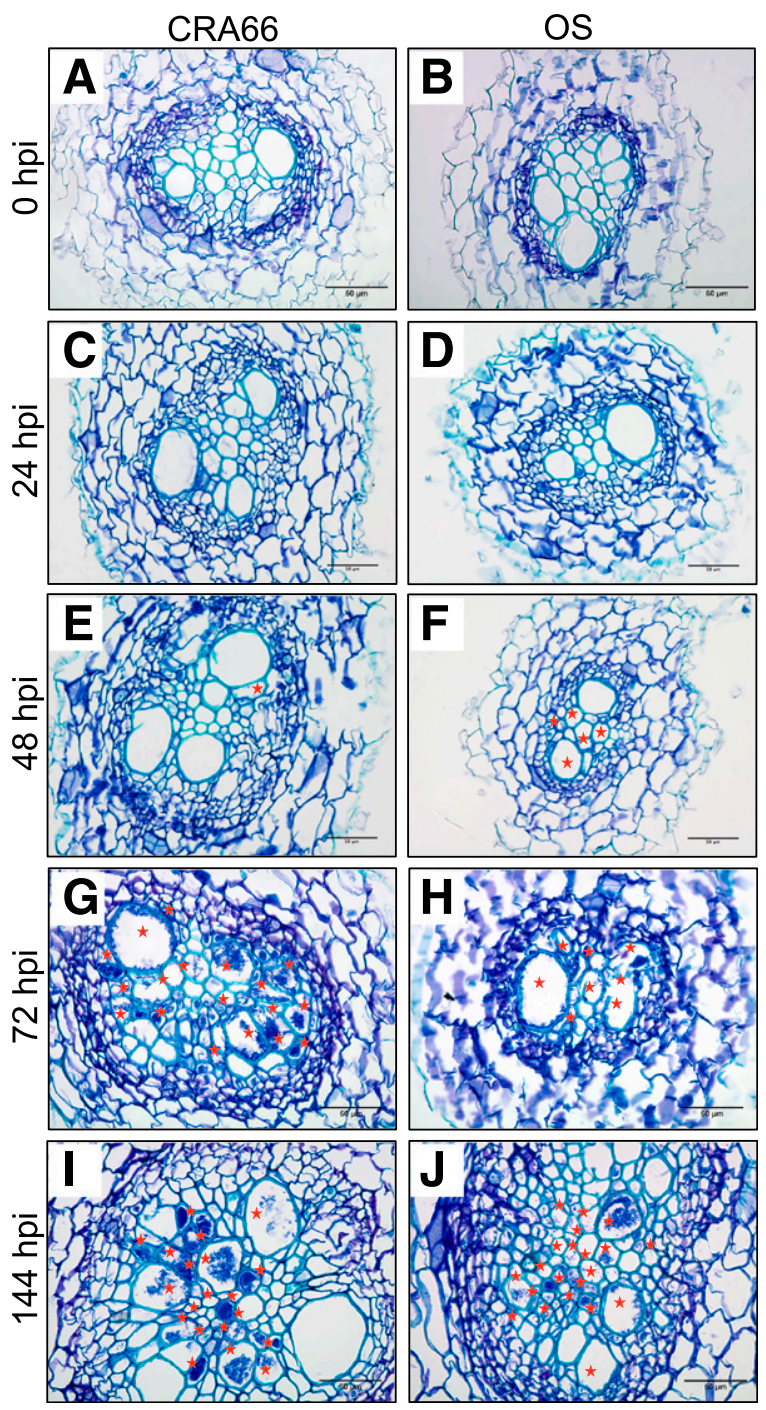

Fig. 8. Ralstonia solanacearum colonization of CRA66 and OS at $0,24,48$, 72 , and $144 \mathrm{~h}$ postinoculation (hpi) observed with light microscopy. Red stars show cells in which $R$. solanacearum is present. Scale bar $=50 \mu \mathrm{m}$. 
To examine this, we used ImageJ to measure the area of the five largest xylem vessels in roots of resistant H7996, resistant CRA66, susceptible WV, and susceptible OS at $0 \mathrm{hpi}$ (Fig. 9). Although vessels of H7996 were significantly larger when compared with OS, no differences were observed among the other varieties. This suggests that xylem vessel area at 0 hpi did not have a role in resistance or susceptibility.

Distribution of $R$. solanacearum in the stem differs between resistant $\mathbf{H 7 9 9 6}$ and susceptible WV. In order to understand whether the variety-specific patterns of bacterial

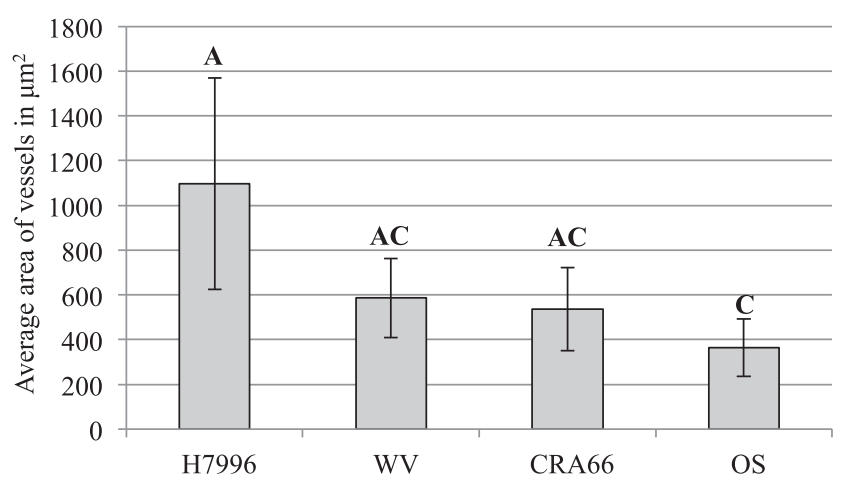

Fig. 9. Xylem vessel size at $0 \mathrm{~h}$ postinoculation (hpi) is unrelated to resistance or susceptibility. Average area of the top five largest xylem vessels for each variety (resistant H7996, susceptible WV, resistant CRA66, and susceptible OS) at 0 hpi. The average of four independent replicates is shown. Letters indicate significance using a one-way analysis of variance followed by Tukey's test at $P<0.05$. distribution found in the root were paralleled in infected shoots, we observed the pattern of bacterial colonization in the hypocotyls of H7996 and WV at 144 hpi, using both SEM and light microscopy. In H7996, R. solanacearum colonization was restricted to the larger xylem tracheary elements (Fig. 10A and C). In contrast, bacteria colonization in WV was observed in the xylem tracheary elements as well as the parenchyma cells in the pith (Fig. 10B and D). These results show that bacterial colonization is restricted in vascular tissues of both the stem and the root of resistant H7996.

\section{DISCUSSION}

In tomato roots, high levels of bacterial colonization (between $10^{5}$ and $10^{8} \mathrm{CFU} / \mathrm{g}$ fresh weight) have frequently been observed, even in resistant lines that show no wilting symptoms (Grimault and Prior 1993; Ishihara et al. 2012; McGarvey et al. 1999; Nakaho et al. 2004). How plants with these latent infections are able to maintain high levels of resistance is not fully understood. Our data reveal spatiotemporal differences in $R$. solanacearum colonization of resistant H7996 tomato roots compared with roots of susceptible WV and OS. In roots of H7996, we find that bacterial invasion of the vascular cylinder is delayed and, once it occurs, appears spatially restricted to a smaller region within the cylinder. Larger metaxylem elements are not significantly colonized, and cell-wall degeneration is not as apparent within roots of the resistant cultivar. In contrast, $R$. solanacearum colonization of the root vascular cylinder of susceptible WV occurs by $24 \mathrm{hpi}$. Bacteria are found throughout the vascular cylinder and can colonize large meta-xylem elements. Additionally, cell-wall degeneration is apparent and $R$. solanacearum colonization spreads throughout the vascular
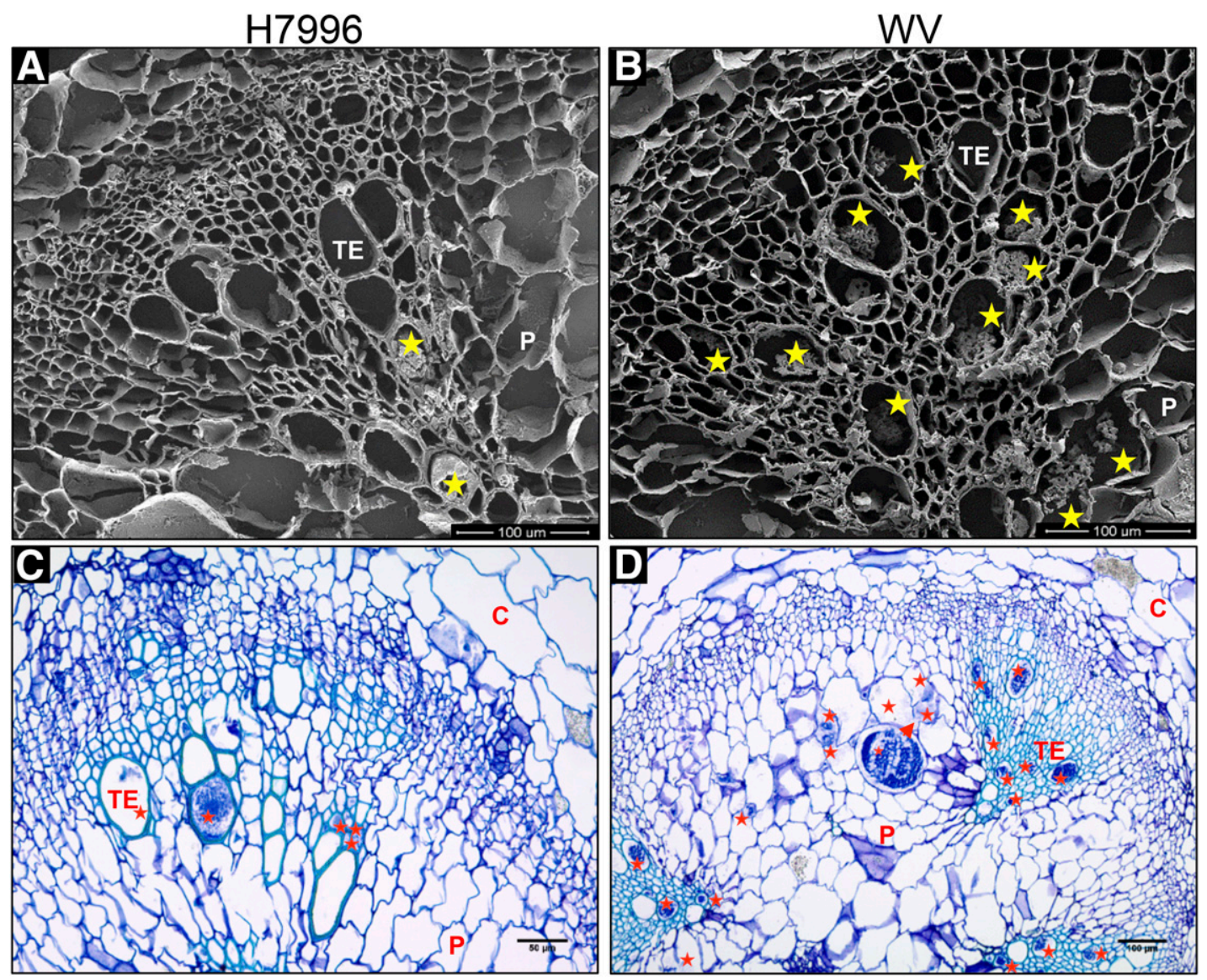

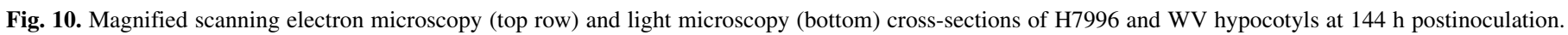

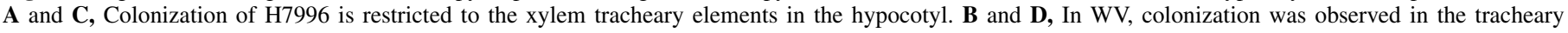
elements along with cells within the pith. TE = tracheary element, $\mathrm{P}=$ pith, $\mathrm{C}=$ cortex, and stars indicate bacteria. 
cylinder and to the root cortex. Our data suggest that early events of bacterial colonization within roots are key to disease outcome. Further, our data indicate that roots have defense mechanisms to restrict bacterial colonization of the vascular cylinder in time and space (spatiotemporal resistance). These defense mechanisms appear to be unrelated to xylem vessel area at the time of inoculation, because we did not detect a relationship between root xylem vessel area and resistant or susceptible plants. The delay in colonization of the root vascular cylinder may enable H7996 to activate defense responses faster than susceptible WV.

Our results indicating that resistance is due to a restriction in bacterial spread in the roots are consistent with observations of resistance in stems. In part, resistance appears to be the result of a limitation of bacterial spread in the stem vascular tissues of latently infected resistant cultivars (Grimault and Prior 1993; Grimault et al. 1994a,b; Nakaho et al. 2000, 2004). The restricted bacterial spread is associated with decreased levels of bacterial colonization in the midstem region (Grimault et al. 1994a, 1995) and is thought to occur in several ways. For example, resistant 'Caraibo', with resistance derived from S. lycopersicum var. cerasiforme (Lebeau et al. 2011), produces tyloses specifically in stem xylem tissue that has been colonized by $R$. solanacearum (Grimault et al. 1994b). Tyloses are invaginations of the membrane of xylem parenchyma cells that are located next to xylem vessels. They prevent xylem sap flow and are often used by the plant as a means of containing air bubbles or pathogens within the xylem (Brodersen and McElrone 2013; Yadeta and Thomma 2013). In contrast to the resistant cultivar, tylose production in stems of the susceptible cultivar occurred much more generally and in cells that had not been colonized by $R$. solanacearum. The authors hypothesized that, in the resistant cultivar, the restricted tylose production limited bacterial colonization but, in the susceptible cultivar, the more nonspecific tylose production was unable to restrict bacterial colonization and contributed to reduced xylem flow to the stem and, thus, to wilting.

In other resistant cultivars, restricted bacterial movement in the stem has not been attributed to tylose production but to induced structural defenses (Nakaho and Allen 2009). Transmission electron microscopy showed that, after infection with $R$. solanacearum strain K60, resistant 'LS-89' developed electron-dense materials in stem xylem vessels and apposition layers in xylem parenchyma cells that were next to colonized xylem vessels (Nakaho and Allen 2009). The resistance in H7996 and LS-89 is likely derived from the same source (Nakaho et al. 2004). Thus, the restriction of stem colonization in resistant H7996 may be due to structural defenses.

Our data highlight the key role of the root vasculature in disease progress, and are consistent with results showing that nonpathogenic $R$. solanacearum hrp mutants are impaired in xylem colonization (Vasse et al. 2000). Xylem invasion and multiplication are also critical steps for $R$. solanacearum susceptibility in Medicago truncatula (Turner et al. 2009). Given that root vascular tissue is critical to disease, the ability to delay colonization of this tissue could be a very important part of resistance in crops.

Although restriction of bacterial spread in the roots-either to the xylem or within the xylem-appears to be a component of resistance, it may not be the only mechanism of resistance in roots. CRA66, like other resistant tomato cultivars, can maintain high pathogen loads without wilting. The early colonization events in CRA66 were similar to those of H7996. However, in contrast to colonization in H7996 at $72 \mathrm{hpi}$, in CRA66, $R$. solanacearum bacteria were found colonizing large meta-xylem vessels, and CRA66 was unable to restrict bacterial spread within the vasculature. Resistance in CRA66 is derived from a different wild source than that in H7996 (Lebeau et al. 2011), and it is possible that resistance in roots of CRA66 operates through a different mechanism. Resistance in each cultivar may be due to different genes and may operate through distinct mechanisms.

Resistant rootstocks are frequently used as a means of control for bacterial wilt. Although the infection process may differ in the field, in which initial inoculum levels are lower than those used in laboratory-based studies (Chellemi et al. 1994), our results reveal that root-mediated resistance may be the result of the root's ability to delay bacteria from colonizing and multiplying quickly in the xylem. Further, our results suggest that roots may have active defense mechanisms that are a critical part of resistance. Roots are complex structures, with over 15 different cell types and tissues. Each cell type has its own transcriptional, protein, and metabolic profile (Brady et al. 2007; Moussaieff et al. 2013; Petricka et al. 2012) and unique responses to environmental stress (Dinneny et al. 2008; Iyer-Pascuzzi et al. 2011). Given the importance of the root vascular cylinder and, specifically, the xylem tissue for resistance, understanding the complex transcriptional events that occur within this tissue is an important next step in our understanding of root defense mechanisms.

\section{ACKNOWLEDGMENTS}

We thank members of the Iyer-Pascuzzi lab for comments on the manuscript, C. Gilpin for help with SEM, M. A. Webb for equipment use, and Purdue University start-up funds for supporting this work.

\section{LITERATURE CITED}

Brady, S. M., Orlando, D. A., Lee, J. Y., Wang, J. Y., Koch, J., Dinneny, J. R., Mace, D., Ohler, U., and Benfey, P. N. 2007. A high-resolution root spatiotemporal map reveals dominant expression patterns. Science 318:801806.

Brodersen, C. R., and McElrone, A. J. 2013. Maintenance of xylem network transport capacity: A review of embolism repair in vascular plants. Front. Plant Sci. 4:108.

Chellemi, D. O., Dankers, H. A., and Olson, S. M. 1994. Evaluating bacterial wilt-resistant tomato genotypes using a regional approach. J. Am. Soc. Hortic. Sci. 119:325-329.

Denny, T. P. 2000. Ralstonia solanacearum-A plant pathogen in touch with its host. Trends Microbiol. 8:486-489.

Denny, T. P., and Baek, S.-R. 1991. Genetic evidence that extracellular polysaccharide is a virulence factor of Pseudomonas solanacearum. Mol. Plant-Microbe Interact. 4:198-206.

Digonnet, C., Martinez, Y., Denance, N., Chasseray, M., Dabos, P., Ranocha, P., Marco, Y., Jauneau, A., and Goffner, D. 2012. Deciphering the route of Ralstonia solanacearum colonization in Arabidopsis thaliana roots during a compatible interaction: Focus at the plant cell wall. Planta 236:1419-1431.

Dinneny, J. R., Long, T. A., Wang, J. Y., Jung, J. W., Mace, D., Pointer, S., Barron, C., Brady, S. M., Schiefelbein, J., and Benfey, P. N. 2008. Cell identity mediates the response of Arabidopsis roots to abiotic stress. Science 320:942-945.

Grimault, V., Anais, G., and Prior, P. 1994a. Distribution of Pseudomonas solanacearum in the stem tissues of tomato plants with different levels of resistance to bacterial wilt. Plant Pathol. 43:663-668.

Grimault, V., Gelie, B., Lemattre, M., Prior, P., and Schmit, J. 1994b. Comparative histology of resistant and susceptible tomato cultivars infected by Pseudomonas solanacearum. Physiol. Mol. Plant Pathol. 44:105-123.

Grimault, V., and Prior, P. 1993. Bacterial wilt resistance in tomato associated with tolerance of vascular tissues to Pseudomonas solanacearum. Plant Pathol. 42:589-594.

Grimault, V., Prior, P., and Anais, G. 1995. A monogenic dominant resistance of tomato to bacterial wilt in Hawaii-7996 is associated with plant colonization by Pseudomonas solanacearum. J. Phytopathol. 143:349-352.

Hanson, P. M., Licardo, O., Hanudin, S., Wang, J. F., and Chen, J. T. 1998. Diallel analysis of bacterial wilt resistance in tomato derived from different sources. Plant Dis. 82:74-78.

Hayward, A. C. 1991. Biology and epidemiology of bacterial wilt caused by Pseudomonas solanacearum. Annu. Rev. Phytopathol. 29:65-87.

Huet, G. 2014. Breeding for resistances to Ralstonia solanacearum. Front. Plant Sci. 5:715.

Ishihara, T., Mitsuhara, I., Takahashi, H., and Nakaho, K. 2012. Transcriptome analysis of quantitative resistance-specific response upon Ralstonia solanacearum infection in tomato. PLoS One 7:e46763.

Iyer-Pascuzzi, A. S., Jackson, T., Cui, H., Petricka, J. J., Busch, W., Tsukagoshi, H., and Benfey, P. N. 2011. Cell identity regulators link development and stress responses in the Arabidopsis root. Dev. Cell 21:770-782.

Jacobs, J. M., Babujee, L., Meng, F., Milling, A., and Allen, C. 2012. The in planta transcriptome of Ralstonia solanacearum: conserved physiological and virulence strategies during bacterial wilt of tomato. mBio 3 .

Lebeau, A., Daunay, M. C., Frary, A., Palloix, A., Wang, J. F., Dintinger, J., Chiroleu, F., Wicker, E., and Prior, P. 2011. Bacterial wilt resistance in 
tomato, pepper, and eggplant: Genetic resources respond to diverse strains in the Ralstonia solanacearum species complex. Phytopathology 101:154-165.

McAvoy, T., Freeman, J., Rideout, S., Olson, S., and Paret, P. 2012. Evaluation of grafting using hybrid rootstocks for management of bacterial wilt in field tomato production. HortScience 47:621-625.

McGarvey, J. A., Denny, T. P., and Schell, M. A. 1999. Spatial-temporal and quantitative analysis of growth and EPSI production by Ralstonia solanacearum in resistant and susceptible tomato cultivars. Phytopathology 89:1233-1239.

Milling, A., Babujee, L., and Allen, C. 2011. Ralstonia solanacearum extracellular polysaccharide is a specific elicitor of defense responses in wiltresistant tomato plants. PloS One 6:e15853.

Moussaieff, A., Rogachev, I., Brodsky, L., Malitsky, S., Toal, T. W., Belcher, H., Yativ, M., Brady, S. M., Benfey, P. N., and Aharoni, A. 2013. Highresolution metabolic mapping of cell types in plant roots. Proc. Natl. Acad. Sci. USA 110:E1232-E1241.

Nakaho, K., and Allen, C. 2009. A pectinase-deficient Ralstonia solanacearum strain induces reduced and delayed structural defences in tomato xylem. J. Phytopathol. 157:228-234.

Nakaho, K., Hibino, H., and Miyagawa, H. 2000. Possible mechanisms limiting movement of Ralstonia solanacearum in resistant tomato tissues. J. Phytopathol. 148:181-190.

Nakaho, K., Inoue, H., Takayama, T., and Miyagawa, H. 2004. Distribution and multiplication of Ralstonia solanacearum in tomato plants with resistance derived from different origins. J. Gen. Plant Pathol. 70:115-119.

Petricka, J. J., Schauer, M. A., Megraw, M., Breakfield, N. W., Thompson, J. W., Georgiev, S., Soderblom, E. J., Ohler, U., Moseley, M. A., Grossniklaus, U., and Benfey, P. N. 2012. The protein expression landscape of the Arabidopsis root. Proc. Natl. Acad. Sci. USA 109:6811-6818.

Plener, L., Manfredi, P., Valls, M., and Genin, S. 2010. PrhG, a transcriptional regulator responding to growth conditions, is involved in the control of the type III secretion system regulon in Ralstonia solanacearum. J. Bacteriol. 192:1011-1019.
Prior, P., and Fegan, M. 2005. Recent developments in the phylogeny and classification of Ralstonia solanacearum. Acta Hortic. 695:127-136.

Remenant, B., Babujee, L., Lajus, A., Medigue, C., Prior, P., and Allen, C. 2012. Sequencing of K60, type strain of the major plant pathogen Ralstonia solanacearum. J. Bacteriol. 194:2742-2743.

Renzi, M., Copini, P., Taddei, A. R., Rossetti, A., Gallipoli, L., Mazzaglia, A., and Balestra, G. M. 2012. Bacterial canker on kiwifruit in Italy: Anatomical changes in the wood and in the primary infection sites. Phytopathology 102: 827-840.

Rivard, C. L., and Louws, F. J. 2008. Grafting to manage soilborne disease in heirloom tomato production. HortScience 43:2104-2111.

Saile, E., McGarvey, J. A., Schell, M. A., and Denny, T. P. 1997. Role of extracellular polysaccharide and endoglucanase in root invasion and colonization of tomato plants by Ralstonia solanacearum. Phytopathology 87:1264-1271.

Schell, M. A. 2000. Control of virulence and pathogenicity genes of Ralstonia Solanacearum by an elaborate sensory network. Annu. Rev. Phytopathol. 38:263-292.

Turner, M., Jauneau, A., Genin, S., Tavella, M. J., Vailleau, F., Gentzbittel, L., and Jardinaud, M. F. 2009. Dissection of bacterial wilt on Medicago truncatula revealed two type III secretion system effectors acting on root infection process and disease development. Plant Physiol. 150:1713-1722.

Vasse, J., Frey, P., and Trigalet, A. 1995. Microscopic studies of intercellular infection and protoxylem invasion of tomato roots by Pseudomonas Solanacearum. Mol. Plant-Microbe Interact. 8:241-251.

Vasse, J., Genin, S., Frey, P., Boucher, C., and Brito, B. 2000. The hrpB and hrp $G$ regulatory genes of Ralstonia solanacearum are required for different stages of the tomato root infection process. Mol. Plant-Microbe Interact. 13: 259-267.

Yadeta, K. A., and Thomma, B. P. H. J. 2013. The xylem as battleground for plant hosts and vascular wilt pathogens. Front. Plant Sci. 4:97.

Yuliar, N. Y. A., and Toyota, K. 2015. Recent trends in control methods for bacterial wilt diseases caused by Ralstonia solanacearum. Microbes Environ. 30:1-11. 